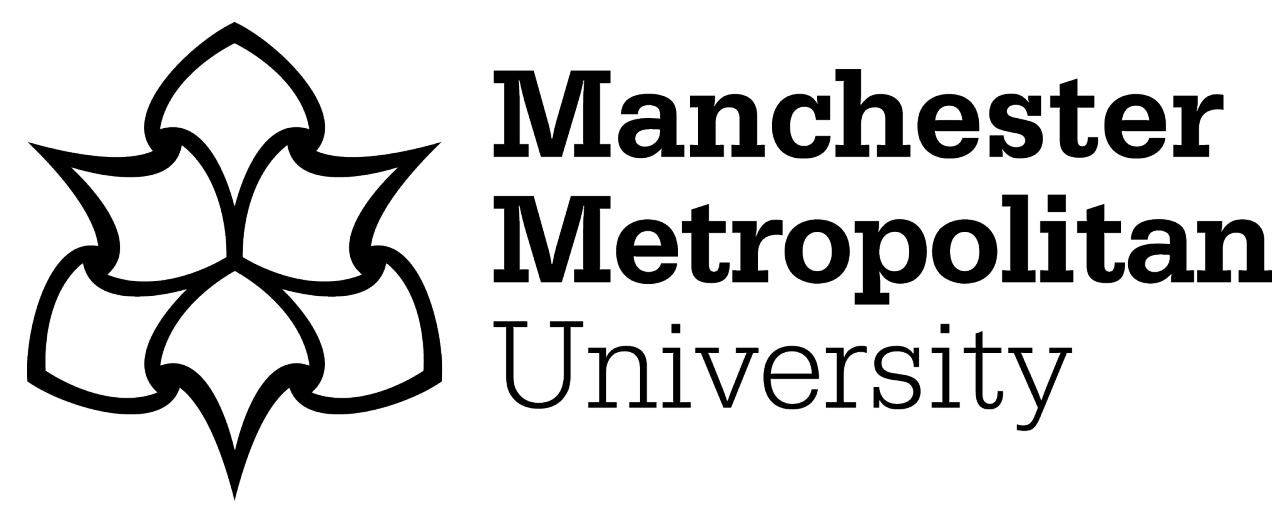

Peeters, G, Cooper, R ORCID logoORCID: https://orcid.org/0000-00033370-5720, Tooth, L, van Schoor, NM and Kenny, RA (2019) A comprehensive assessment of risk factors for falls in middle-aged adults: co-ordinated analyses of cohort studies in four countries. Osteoporosis International, 30 (10). pp. 2099-2117. ISSN 0937-941X

Downloaded from: https://e-space.mmu.ac.uk/623597/

Version: Accepted Version

Publisher: Springer (part of Springer Nature)

DOI: https://doi.org/10.1007/s00198-019-05034-2

Please cite the published version 


\section{A comprehensive assessment of risk factors for falls in middle-aged adults: co-ordinated analyses of cohort studies in four countries}

Geeske Peeters, ${ }^{1,2}$ Rachel Cooper, ${ }^{3}$ Leigh Tooth, ${ }^{2}$ Natasja M van Schoor, ${ }^{4}$ Rose Anne Kenny ${ }^{1,5,6}$

${ }^{1}$ Global Brain Health Institute, Trinity College Dublin, Ireland

${ }^{2}$ Faculty of Medicine, School of Public Health, The University of Queensland, Brisbane, Australia

${ }^{3}$ Musculoskeletal Science and Sports Medicine Research Centre, Department of Sport and Exercise Sciences, Faculty of Science and Engineering, Manchester Metropolitan University, Manchester, UK

${ }^{4}$ Amsterdam UMC, Vrije Universiteit Amsterdam, Department of Epidemiology and Biostatistics, Amsterdam Public Health, Amsterdam, The Netherlands

${ }^{5}$ Mercer's Institute for Successful Ageing, St James's Hospital, Dublin, Ireland

${ }^{6}$ The Irish Longitudinal Study on Ageing, Trinity College, Dublin, Ireland

Address for correspondence: Dr Geeske Peeters, Global Brain Health Institute, Trinity College Institute of Neuroscience, Trinity College Dublin, Lloyd Building, Dublin 2, Ireland, E geeske.peeters@gbhi.org, T+353(0)18961131

\section{Acknowledgements}

Some of the research on which this article is based was conducted as part of the Australian Longitudinal Study on Women's Health by The University of Newcastle and The University of Queensland. We are grateful to the women who provided the survey data and to the Australian Government Department of Health for funding. The NSHD is funded by the UK Medical Research Council. We are grateful to NSHD study members for their continuing support. NSHD data used in this publication are available to bona fide researchers upon request to the NSHD Data Sharing Committee via a standard application procedure. Further details can be found at http://www.nshd.mrc.ac.uk/data doi: 10.5522/NSHD/Q101; doi: 10.5522/NSHD/Q102. The Longitudinal Aging Study Amsterdam is supported by a grant from the Netherlands Ministry of Health Welfare and Sports, Directorate of Long-Term Care. The data collection [in 2012-2013 and 2013-2014] was financially supported by the Netherlands Organization for Scientific Research (NWO) in the framework of the project "New Cohorts of young old in the $21^{\text {st }}$ century" (file number 480-10014). The Irish Longitudinal Study on Ageing (TILDA) is funded by the Irish Government, the Atlantic Philanthropies and Irish Life PLC. We are grateful to all of the TILDA respondents for participating in 
the study. Researchers interested in using TILDA data may access the data for free from the following sites:

-Irish Social Science Data Archive at University College Dublin http://www.ucd.ie/issda/data/tilda/;

-Interuniversity Consortium for Political and Social Research (ICPSR) at the University of Michigan http://www.icpsr.umich.edu/icpsrweb/ICPSR/studies/34315.

GP was supported by a Global Brain Health Institute Fellowship. RC was supported by the UK Medical Research Council (programme code: MC_UU_12019/4). The funders had no role in the study design, data collection, data analysis, data interpretation, writing of the report or the decision to submit the article for publication.

\section{Conflict of interest}

Geeske Peeters, Rachel Cooper, Leigh Tooth, Natasja van Schoor and Rose Anne Kenny declare that they have no conflicts of interest. 


\section{Abstract}

Purpose: Between ages 40-44 and 60-64 years, the annual prevalence of falls triples suggesting that middle-age may be a critical life stage for preventive interventions. We aimed to identify demographic, health and lifestyle factors associated with falls in adults aged 50-64 years. Methods: Harmonised data were used from four population-based cohort studies based in Australia (Australian Longitudinal Study on Women's Health, $n=10641$, 51-58 years in 2004), Ireland (The Irish Longitudinal Study on Ageing, $n=4663,40-64$ years in 2010), the Netherlands (Longitudinal Aging Study Amsterdam, n=862, 55-64 years in 2012-13) and Great Britain (MRC National Survey of Health and Development, $n=2987,53$ years in 1999). Cross-sectional and prospective associations of 42 potential risk factors with self-reported falls in the past year were examined separately by cohort and gender using logistic regression. In the absence of differences between cohorts, estimates were pooled using meta-analysis.

Results: In cross-sectional models, nearly all risk factors were associated with fall risk in at least one cohort. Poor mobility (pooled $\mathrm{OR}=1.71, \mathrm{Cl}=1.34-2.07$ ) and urinary incontinence (OR range=1.53-2.09) were consistently associated with falls in all cohorts. Findings from prospective models were consistent. Statistically significant interactions with cohort and sex were found for some of the risk factors.

Conclusion: Risk factors known to be associated with falls in older adults, were also associated with falls in middle-age. Compared with findings from previous studies of older adults, there is a suggestion that specific risk factors, for example musculoskeletal conditions, may be more important in middle-age. These findings suggest that available preventive interventions for falls in older adults may also benefit middle-aged adults, but tailoring by age, sex and country are required.

Keywords: accidental falls; mobility; middle aged; population health

Mini abstract: We identified demographic, health and lifestyle factors associated with falls in adults aged 50-64 years from Australia, The Netherlands, Great Britain and Ireland. Nearly all factors were associated with falls, but there were differences between countries and between men and women. Existing falls prevention programs may also benefit middle-aged adults. 


\section{Introduction}

Falls in older adults are a major public health challenge; they are an important cause of injuries and impact on social participation, fear of falling again and health service utilisation [1-3]. However, falls among middle-aged adults are largely ignored. This is despite the fact that the estimated annual prevalence of falls triples from $9 \%$ in $40-44$ year old adults to $28 \%$ in $60-64$ year old adults [4], suggesting that middle-age may be a critical life stage for preventive interventions.

Current evidence-based guidelines for the prevention of falls focus on adults aged 65 and over and recommend assessment and targeting of contemporaneous risk factors, including demographic, health, lifestyle and environmental related factors [5-10]. However, less evidence is available on risk factors for falls in adults under the age of 65 . The current generation of middle-aged adults differs from previous generations with regards to important demographic and health indicators including greater educational attainment and higher obesity prevalence [11]. Greater educational attainment contributes to higher adult socio-economic position, healthier lifestyles and better health [12-14], while in contrast high BMI predisposes to conditions such as diabetes and osteoarthritis, which are associated with increased fall risk [9]. As such, the current generation of middle-aged adults are therefore not necessarily healthier than their parents' generation. These generational differences, together with the lower prevalence of health problems in middle-age than in older age, likely translate to different risk factor profiles for falls in middle-aged adults than in older adults.

In a cohort of over 4000 Australian women aged 50-55 years, being overweight or obese, having poor physical functioning and vision problems were consistently associated with an increased fall risk throughout middle-age [15]. That study identified 15 other risk factors (e.g. urinary incontinence, depression and assistance with daily activities) that were associated with an increased fall risk at some but not all time points throughout middle-age [15]. While the sample was large, the prevalence for some of the risk factors was low, which may explain the inconsistent findings. Studies of middle-aged adults from Finland and New Zealand identified alcohol consumption and medication use as risk factors of fall-related injury requiring hospital admissions [16-18], but did not find evidence that being overweight or obese was a risk factor [18]. Verification of these findings in a large sample that includes men and women is required to obtain better insight into the risk factors for falls in middle-aged adults.

The prevalence of falls is higher in women than in men, both in middle-age and later life $[4,9]$. Research by our consortium has shown substantial variation in the prevalence of falls, even within 
age- and sex-groups, between representative samples from Australia, The Netherlands, Great Britain and Ireland.[4] For example, in adults aged 60-64 years, the prevalence ranged from $20 \%$ in Irish women to 31\% in Australian women and from 14\% in British men to 24\% in Dutch men. Differences between countries have been found in the prevalence of falls, prevalence of risk factors for falls and associations between risk factors and falls in adults aged 65 years and older in SHARE including data from 18596 participants from 12 European countries [19]. That study also found that the differences in associations between countries were largely explained by differences in the prevalence of risk factors. Hence, risk factor profiles may differ by sex and country.

This study aimed to identify demographic, health and lifestyle risk factors for falls in middle-aged adults in Australia, The Netherlands, Great Britain and Ireland. Associations of potential risk factors with falls were examined separately by (a) country, and (b) sex. The focus was on demographic, health and lifestyle factors that have been found to be associated with falls in older adults $[9,10]$, and have informed development of recommended preventive strategies in the community setting [5-8]. If the same risk factors are important in middle-age as at older ages, this would support earlier commencement of interventions that address these risk factors, with potential benefits sustained into older age. If different risk factors are important in middle-age, different strategies may need to be developed for the prevention of falls in midlife.

\section{Methods}

\section{Study design and participants}

The STrategies for Early Prevention of falls (STEP) consortium uses data from four cohort studies in Australia, The Netherlands, Great Britain and Ireland. The cohorts were selected based on the following criteria: (i) representative, population-based sample of adults aged 50-64 years; (ii) available data on falls in the previous year at one or more data collection waves; and (iii) available data on the majority of potential risk factors. The selection of the data collection waves for each cohort and procedures for data harmonisation are described in detail in Appendix 1. Although we have previously used these data to estimate prevalence of falls from ages 40 to 64 [4], the current analyses were limited to ages 50 to 64 as only one study recorded falls comparably between ages 40 and 50 and this was in a relatively small sample. Moreover, as the primary focus of current efforts to reduce falls risk is among adults aged 65 and older, we decided that it was most appropriate to focus on the next oldest age group in these analyses. Below we describe the design and participants for each of the cohorts. 
The Australian Longitudinal Study on Women's Health (ALSWH) is a prospective study of the health and well-being of four generations of women $[20,21]$. Samples were randomly drawn from the national Medicare health insurance database, which includes all Australian citizens and permanent residents, with intentional over-sampling of women from rural and remote areas [20]. The study was approved by Ethics Committees of the Universities of Newcastle and Queensland. All participants provided informed consent. Data were collected through self-completed surveys either completed in paper form or electronically. In 1996, 13714 participants from the 1946-51 cohort (aged 45-50 years at baseline) returned the baseline survey (estimated response rate 54\%). Follow-up surveys have been completed at approximately 3-year intervals. Falls data were available from the 2004 survey onward. For the current analysis, data were used from surveys completed in 2004 ( $n=10641$, aged 52-58), 2007 ( $n=10525$, aged 55-61), 2010 ( $n=9887$, aged 58-64) and 2013 ( $n=4883$, aged 62-64) with complete data on age and falls.

The Longitudinal Ageing Study Amsterdam (LASA) is an ongoing interdisciplinary cohort study on predictors and consequences of changes in physical, cognitive, emotional, and social functioning in men and women aged 55-85 years at baseline in 1992-93. A random sample stratified for age, sex, and expected 5-year mortality was drawn from the population registries of 11 municipalities in the Netherlands [22]. In 2012-13, the original sample was replenished with 1023 participants aged 55-65 years. Data were collected through self-completed surveys and structured interviews with clinical assessment conducted by trained interviewers. The VU University Medical Centre Ethical Review Board approved the study. All participants provided informed consent. As falls data were available in the correct age-range for participants in the 2012-13 cohort only, data from this cohort were used for the current analyses. In total, data were used from 862 participants aged 55-64 years with complete data on age and falls.

The MRC National Survey of Health and Development (NSHD) is an ongoing cohort study of a nationally representative sample of 5,362 males and females born in England, Scotland and Wales during one week in March 1946 [23,24]. The sample have now been followed up prospectively 24 times across life since birth. Falls data for these analyses were ascertained from nurse interviews during two of the most recent waves of data collection; at age 53 (in 1999), 3035 participants were successfully contacted, of whom 2984 received a home visit from a trained nurse; at age 60-64 (in 2006-2010), 2856 eligible participants were invited for assessment at one of six clinical research facilities or to be visited by a research nurse at home of whom 2229 were assessed. Relevant ethical approval was received from the North Thames Multi-Centre Research Ethics Committee (MREC 
98/1/121) for the 1999 assessment and from the Central Manchester Local Research Ethics Committee (07/H1008/245) and the Scottish A Research Ethics Committee (08/MRE00/12) for the 2006-2010 assessment. All participants provided informed consent. In total, data were used from 2987 participants with complete data on falls at age 53 and 2210 participants at age 60-64.

The Irish Longitudinal Study on Ageing (TILDA) is an ongoing cohort study designed to achieve a representative sample of community-dwelling people aged 50 years or older in Ireland [25]. A random sample of 25600 residential addresses in Ireland were selected with stratification for socioeconomic status, age and geography. All persons aged 50 years and over (primary respondents) and their spouses or partners of any age (secondary respondents) were eligible. Each address was visited by field staff. Participants completed an interviewer-led computer-assisted questionnaire, a self-completed questionnaire and a research nurse-led health assessment. All participants signed informed consent. Ethical approval has been obtained from the Trinity College Dublin Research Ethics Committee. Baseline data from the 8504 primary and secondary participants were collected between October 2009 and July 2011. Follow-up waves were completed in 2012/13 and 2014/15. For the current analyses, data were used from participants aged 50-64 years with complete data on age and falls in 2010 ( $n=4663), 2012$ ( $n=3825)$ and $2014(n=3035)$.

\section{Falls}

In LASA, TILDA and NSHD, participants who responded 'yes' to the question "Have you fallen in the last year?" were classified as having had a fall. In ALSWH, participants who responded 'yes' to any one of the following three questions were classified as having had a fall: "In the last 12 months, have you: (i) had a fall to the ground? (ii) been injured as a result of a fall? and (iii) needed to seek medical attention for an injury from a fall?"

\section{Demographic, health and lifestyle factors}

Variables were selected based on known associations with fall risk in older adults. Variables were harmonised and included in the current analyses only if data were available for at least three of the cohorts. For a description of how each factor was measured in each cohort and how the variables were harmonised across the cohorts, please refer to Appendix 1. Data harmonisation was undertaken following a standardised approach to ensure that similar measures from different studies were as comparable as possible. The variables include:

- Demographics: age, sex, education, marital status, number of people in the household, retirement status, urbanisation grade; 
- Health: osteoarthritis, rheumatoid arthritis, cancer, anxiety, depression, diabetes, heart disease, hypertension, lung disease, stroke, number of chronic conditions (range $0-4$ ), benzodiazepine use, number of medications, polypharmacy, self-rated health, diastolic and systolic blood pressure, body mass index (BMI), dizziness, functional limitations (range 0-4), hearing problems, vision problems, pain, sleeping problems, urinary incontinence, immediate recall, delayed recall, verbal fluency, grip strength, mobility, use of a walking aid.

- Lifestyle: alcohol use, smoking status, level of leisure time physical activity.

\section{Statistical analyses}

Cross-sectional associations between each of the potential risk factors and fall status were examined using logistic regression adjusted for age and sex. To examine whether associations differed by cohort and sex, the models were initially run in the total sample including product terms for cohort (cohort $\times$ risk factor) and sex (sex $\times$ risk factor). For each product term, models with and without that product term were compared using the likelihood ratio test. The final univariate models were run for each of the cohorts separately, and the results were combined using fixed effect meta-analyses. The $I^{2}$ statistic was used as a measure of heterogeneity between cohorts. Combined results were only presented if there was no evidence for interaction by cohort ( $p$-value for interaction with cohort $>0.01)$ and low to moderate heterogeneity $\left(I^{2}<70 \%\right.$, while acknowledging that the confidence interval around the $\mathrm{I}^{2}$ is likely wide due to having a maximum of 4 data points). Given the low prevalence of some of the risk factors, it was not feasible to stratify by both cohort and sex. Therefore, in case of a statistically significant interaction with sex, models were additionally run for the total sample after stratification by sex as a post hoc analysis. To reduce the risk of type I error given the multiple comparisons, the significance level was set at 0.01 and $99 \%$ confidence intervals (CI) were presented. To ensure maximum coverage of the 50-64 year age-range within each of the cohorts, data were used from multiple waves where available (ALSWH, NSHD, TILDA). Robust standard errors were used to account for within-person variation due to repeated measures within cohorts.

To examine potential reverse causality, prospective models were run in which risk factors assessed at one data collection wave were associated with fall status measured th the subsequent wave. These models were included as confirmatory analyses of the cross-sectional models rather than described as the main models, because (i) data from the LASA study could not be included in the prospective models (falls were measured at baseline only), and (ii) some risk factors were measured at the last data collection wave only and no follow-up data on falls were available. The prospective 
models were built up in the same way as described for the cross-sectional analyses, with the exception that results were not pooled across the cohorts because of the greater degree of heterogeneity between studies expected due to variation in the length of intervals between data collection waves: 3 years in ALSWH, 10 years in NSHD and 2 years in TILDA. All analyses were done using Stata version 14.2 (StataCorp LP, US).

\section{Results}

In ALSWH, all participants were women and the average age was 55.0 years $(S D=1.5)$ in $2004,58.0$ $(S D=1.5)$ in 2007, $61.1(S D=1.5)$ in 2010 and 63.1 (SD=0.8) in 2013. In LASA, half the sample were women, and the average age was $59.7(S D=2.8)$ in 2012. In NSHD, half the sample were women and the average age was 53.5 (SD=0.2) in 1999 and 63.4 (SD=1.1) in 2006-10. In TILDA, just over half the sample were women and the average age was $56.7(S D=43.3)$ in 2010, $57.6(S D=3.9)$ in 2012 and $58.6(S D=3.4)$ in 2014. Other characteristics of the four samples are described in Table 1.

In cross-sectional models, statistically significant interactions with cohort were found for: sex, urbanisation grade, heart disease, hypertension, anxiety, BMI, dizziness, sleeping problems and urinary incontinence (Table 2). For all but two risk factors (i.e. heart disease, hypertension), the heterogeneity in associations across the cohorts was high $\left(1^{2}>70 \%\right)$ and the results were presented for each cohort separately. While nearly all factors were statistically significantly associated with fall risk in at least one of the cohorts, only mobility was consistently associated with falls in all cohorts that measured it (poor vs good mobility: pooled $\mathrm{OR}=1.71, \mathrm{Cl}=1.34-2.07$ ). Demographic factors that were associated with falls in at least two of the cohorts, included age, sex, marital status, number of other people in the household and urbanisation grade. Health factors that were associated with falls in at least two of the cohorts, included self-rated health, number of chronic conditions, osteoarthritis, rheumatoid arthritis, heart disease, lung disease, stroke, number of medications, polypharmacy, benzodiazepine use, use of a walking aid, functional limitations, dizziness, pain, hearing problems, sleeping problems and urinary incontinence. Of the lifestyle factors, only level of physical activity was associated with a fall risk in at least two of the cohorts (inactive vs high: pooled $\mathrm{OR}=1.30, \mathrm{Cl}=1.19-1.41)$.

In prospective models, statistically significant interactions with cohort were found for: age, sex, number of other people in the household, urbanisation grade, self-rated health, heart disease, anxiety, BMI, dizziness and urinary incontinence (Table 3). For all but one risk factor (i.e. number of others in household), the heterogeneity in associations across the cohorts was high. In ALSWH and 
TILDA, but not in NSHD, the findings from the prospective models were consistent with the findings from the cross-sectional models (i.e. the ORs were in the same direction and range).

The risk factors for which statistically significant interactions with sex were found differed between the cross-sectional and prospective models. Cross-sectionally, significant interactions with sex were found for the risk factors number of other people in the household, number of chronic conditions, heart disease, $\mathrm{BMI}$, and urinary incontinence (Table 2). For urinary incontinence, stronger associations with falls were found in men than in women (Table 4). For number of chronic conditions and heart disease, stronger associations with falls were found in women than in men. Prospectively, significant interactions with sex were found for the risk factors cancer, heart disease and verbal fluency (Table 3). For heart disease, a strong association was found in women, but not in men. For cancer and verbal fluency, the ORs suggested different associations in men and women, but in neither group did the associations reach statistical significance.

\section{Discussion}

Many of the demographic, health and lifestyle risk factors known to be associated with falls in older adults were also associated with falls in middle-aged adults. Poor mobility and urinary incontinence were consistently associated with a higher fall risk in all cohorts that measured it. For the other risk factors, associations with falls varied between cohorts. Overall, the associations found in the crosssectional models were supported by the findings from the prospective models in the Australian and Irish cohorts. Statistically significant interactions with sex suggest differences in risk factors for falls among middle-aged men and women.

\section{Demographic risk factors}

Similar to older adults [26], middle-aged women have a higher fall risk than men. In line with findings from a meta-analysis of 7 studies in older adults [9], we found no statistically significant association between level of education and fall risk. Consistent with findings from a study based on hospital admission records of 19518 adults aged 20-92 in Finland, being single, widowed, divorced or separated was associated with an higher fall risk than being married [18]. The association between number of other people in the household and fall risk appeared consistent across the four cohorts.

To our knowledge, no other study has examined the association between retirement status and fall risk. Being retired was associated with an increased risk of falls in the British cohort, but not in the Dutch and Irish cohorts. The prevalence of retirement was much higher in the British cohort (61.7\%) 
than in the Dutch (16.0\%) and Irish (13.0-15.0\%) cohorts, which reflects the higher average age and lower age of eligibility for retirement for women in this birth cohort in Great Britain. Differences between countries may also relate to different primary reasons for retirement; early and late retirement are influenced by financial circumstances and health [27-29], which relate differently to fall risk.

\section{Health factors}

In all four cohorts included in our study, participants with poor self-rated health (SRH) were found to have elevated odds of falling when compared with those reporting excellent SRH (pooled OR: 3.20 (95\% Cl: 2.55-3.84)). This estimate is substantially higher than that reported in a meta-analysis of 6 studies of older adults (pooled $\mathrm{OR}=1.50,95 \% \mathrm{Cl}=1.15-1.96$ ) [9]. Likewise, the $\mathrm{OR}$ for number of chronic conditions (including diabetes, heart disease, lung disease and cancer) was somewhat higher in our study (re-analysed as a continuous variable, range $0-4$ : pooled $\mathrm{OR}=1.37, \mathrm{Cl}=1.31-1.43$ ) than in a meta-analysis of 10 studies in older adults (pooled $\mathrm{OR}=1.23, \mathrm{Cl}=1.16-1.30$ ).[9] Similarly, associations with fall risk were stronger for osteoarthritis, rheumatoid arthritis, diabetes, stroke, pain and urinary incontinence in the current sample of middle-aged adults, than in the metaanalyses of studies conducted in older adults [9]. These findings indicate a stronger contrast in fall risk between those with and without chronic conditions in midlife than between those with and without chronic conditions at older ages. This may be explained by the higher prevalence of multimorbidity at older ages and by the age-related decline in balance and mobility independent of chronic conditions that reduces the contrast between those with and without multimorbidity at older ages. At younger ages people with these conditions are a more select, higher risk group who may benefit from targeted falls prevention strategies.

The findings for medication use and fall risk were similar across the cohorts (Table 2). Compared with findings from a meta-analysis in older adults, the ORs suggest stronger associations in the middle-aged adults than in the older adults. For each additional medication, the OR was 1.13 $(\mathrm{Cl}=1.11-1.15)$ in the current middle-aged sample, whereas the unadjusted OR pooled across data from 10 studies was 1.06 ( $\mathrm{Cl}=1.04-1.08)$ in older adults [9]. For benzodiazepine use, the OR was 1.86 $(\mathrm{Cl}=1.53-2.19)$ in the current sample, compared with $1.38(\mathrm{Cl}=1.15-1.66)$ in older adults [9]. These findings suggest that medication-related interventions to prevent falls recommended for older adults, such as medication review and avoidance of benzodiazepine use [5-8], may also be relevant for younger adults. 
Along with a history of falls, poor gait and balance are generally regarded as the most important risk factors of falls in older adults [30]. We found that use of a walking aid was a strong predictor for falls, even though very few people in the sample reported using a walking aid. Correspondingly, poor mobility as measured with a walking test was associated with a greater fall risk, but only in the crosssectional models. However, the prospective models for mobility were based on data from the Irish cohort only and given the fluctuations between cohorts, verification in a different cohort is required. The ORs for functional limitations were of a similar magnitude to those previously reported in older adults [9].

In a previous paper using ALSWH data only, obesity was identified as an important risk factor for falls in middle-age [15]. In the current analyses, a statistically significant prospective association was found in the Australian cohort again, but not in the other three cohorts. However, we did find a significant interaction with sex, and after stratification found that the association between obesity and falls was stronger in women than in men (Table 4). The Australian cohort included women only, which may explain the differences in findings between the cohorts.

Systematic reviews of observational studies in older adults that examined associations between measures of cognitive function and fall risk, found stronger evidence for associations with fall risk for executive function than for memory [31,32]. In contrast, in the British cohort we found fairly strong cross-sectional associations with fall risk for immediate and delayed recall, but not with verbal fluency, a measure of executive function. However, these associations with recall tests were not found in the Dutch cohort and, while statistically significant, the effect estimate for delayed recall was much lower in the Irish cohort than in the British cohort. Moreover, the cross-sectional associations were not confirmed in the prospective models. One study examining associations between cognitive functions and fall risk used data from the LASA study, but included participants over the age of 65 only. In that study, a significant association was found between immediate recall and fall risk, but only in adults over the age of 75 [33]. In a study among 1947 adults aged 70 years and older, immediate recall was not associated with fall risk, but decline in immediate recall over 8 years follow-up was associated with an increased fall risk [34]. Hence, cognitive risk factors may be more important at older ages when the prevalence of cognitive decline is higher.

The association between hearing problems and fall risk in middle-aged adults was similar in the cross-sectional and prospective models, and in line with findings in older adults [9]. The associations between vision problems and fall risk varied across the cohorts. Reviews of studies 
conducted in older adults also describe inconsistencies in findings between studies examining associations between objective measures of vision and fall risk $[35,36]$. These inconsistencies may partly be explained by differences in sample characteristics and measurement of vision. It may also be that it is the accumulation of sensory problems that is important for fall risk rather than problems with specific sensory modalities $[37,38]$, In the current study, no data were available on other sensory modalities, such as proprioception, depth perception and contrast sensitivity $[39,40]$. Hence, further research is required to gain a better understanding of the role of sensory functions and fall risk in middle-aged adults.

\section{Lifestyle factors}

Similar associations between lifestyle factors and fall risk were found in middle-age as in older adults. Both never drinking alcohol and high-risk drinking may increase fall risk [41,42], although in the current sample the association was significant in the Australian cohort only. Inactivity, measured either with questionnaires [43] or accelerometers [44], has been associated with increased fall risk in older adults. This is consistent with our findings in middle-aged adults and highlights the potential benefits of extending targeted physical activity interventions which reduce inactivity with the aim of preventing or delaying functional decline in older adults to include middle-aged adults [45]. There is little evidence for an association between smoking and fall risk in middle-aged or older adults [46]. Our findings suggest that ex-smokers may have a higher fall risk than never smokers, but this was statistically significant in the Australian cohort only and was modest.

There were substantial differences in the risk factor profiles between the four cohorts. This is in line with findings from SHARE, which found substantial differences in the risk factors associated with falls in older adults across 12 European countries. That study also demonstrated that between-country differences in the prevalence of falls strongly attenuated after adjusting for differences in risk factors [19]. Country differences may reflect true differences between countries due to differences in demographics, health, lifestyle and health care systems, but may also be an artefact of differences in study design (e.g. selection criteria, sample size, measurement of risk factors), which cannot be fully removed by harmonisation. In LASA, only poor mobility was associated with a statistically significant increased fall risk. While the LASA sample was substantially smaller than the other three samples, a sample of 862 participants with $25 \%$ fallers should be large enough to detect statistically significant associations. For some risk factors with a low prevalence, for example benzodiazepine use $(4.7 \%$ in LASA), the OR was of a similar magnitude to that in the other cohorts (LASA: OR=1.77, $\mathrm{Cl}=0.74-4.23$; other cohorts: ORs=1.68-2.39), but with wider confidence intervals. However, for many risk factors, 
the ORs were substantially lower in LASA than in the other three cohorts, which cannot be explained by a lack of statistical power. Therefore, replication of these analyses in a different Dutch cohort is recommended.

The findings in the cross-sectional and prospective models in the Australian and Irish cohorts were remarkably consistent. This makes reverse causation less likely, although it cannot be ruled out. There were substantial differences in the findings from the cross-sectional and prospective models in the British cohort. This contrast is likely explained by the longer duration between data collection waves (10 years) in the British than in the Australian ( 3 years) and Irish ( 2 years) cohorts. A proportion of participants classified as not having chronic conditions at the first assessment may have developed chronic conditions such as diabetes or lung disease during follow-up. This may have reduced the contrast between the groups and diluted the association with fall risk. As middle-age is a life stage during which many changes in lifestyle and health occur, a 10-year interval may be too long to detect meaningful associations with fall risk without appropriately taking into account changes in risk factor profiles.

Risk factors known to be associated with falls in older adults, were also associated with falls in middle-aged adults. This suggests that evidence-based preventive interventions developed for older adults may also be of benefit to middle-aged adults. However, as discussed above, there are differences in the strength of associations between middle-aged and older adults. Moreover, there are differences in risk factor profiles by country and sex. Existing preventive interventions may therefore be more effective if tailored to age, sex and country. Future research is required to examine the (cost-)effectiveness of preventive interventions targeting the identified risk factors.

Strengths include using data from 20257 participants from four cohorts based in different countries. This allowed us to examine differences in associations between a comprehensive range of different risk factors and falls between cohorts and between women and men. Moreover, the large sample gave us sufficient statistical power to examine risk factors with a low prevalence in middle-age, but with a potentially large impact on fall risk, such as stroke and benzodiazepine use. However, results need to be interpreted with caution as we did not test whether the risk factors identified are independent of each other. Other limitations of our study include that not all cohorts had data available on all potential risk factors of interest. For example, we were unable to conduct meaningful comparisons of environmental factors. In addition, while we were able to investigate some objective measures of physical performance i.e. grip strength and mobility, there are other 
potentially important measures of performance such as standing balance which we were unable to study and which may therefore warrant investigation in future studies. Another potential limitation is that for some variables, details in the data were lost due to data harmonisation. Although our data harmonisation approach was valid and feasible, it is also possible that some differences in the observed findings between the studies may still be due to differences in measures. Bias may also have been introduced as data on falls and many of the risk factors were self-reported. However, this would not be expected to have impacted greatly on the findings and their comparison with studies of older adults as falls in community-based samples are usually ascertained via self-report.

In conclusion, many of the demographic, health and lifestyle risk factors known to be associated with falls in older adults, were also associated with falls in middle-aged adults. However, there are differences in the strength of the associations between middle-aged and older adults with some factors such as musculoskeletal conditions being potentially more important at younger ages. Poor mobility and urinary incontinence were the only risk factors that were consistently associated with a higher fall risk across the four countries. Country differences in risk factor profiles may reflect differences in the prevalence of both the risk factors and falls and/or be driven by differences in study design. Statistically significant interactions with sex were found for five of the risk factors, suggesting that there are some differences in risk profiles for men and women. Future research should verify whether available preventive interventions that target the identified risk factors are also beneficial for middle-aged adults, and whether tailoring by age, sex and country is required.

\section{Reference list}

1. Collerton J, Kingston A, Bond J, Davies K, Eccles MP, Jagger C, Kirkwood TB, Newton JL (2012) The personal and health service impact of falls in 85 year olds: cross-sectional findings from the Newcastle 85+ cohort study. PLoS One 7 (3):e33078. doi:10.1371/journal.pone.0033078

2. Stel VS, Smit JH, Pluijm SM, Lips P (2004) Consequences of falling in older men and women and risk factors for health service use and functional decline. Age Ageing 33 (1):58-65

3. Peeters GM, Jones M, Byles J, Dobson AJ (2015) Long-term Consequences of Noninjurious and Injurious Falls on Well-being in Older Women. J Gerontol A Biol Sci Med Sci 70 (12):1519-1525. doi:10.1093/gerona/glv102

4. Peeters G, van Schoor NM, Cooper R, Tooth L, Kenny RA (2018) Should prevention of falls start earlier? Co-ordinated analyses of harmonised data on falls in middle-aged adults across four population-based cohort studies. PLoS One 13 (8):e0201989. doi:10.1371/journal.pone.0201989 
5. Preventing Falls and Harm From Falls in Older People - Best Practice Guidelines for Australian Community Care 2009 (2009). Australian commission on safety and quality in health care, Commonwealth of Australia

6. National Steering Group on the Prevention of Falls in Older People and the Prevention and Management of osteoporosis throughout life (2008) Strategy to Prevent Falls and Fractures in Ireland's Ageing Population. Health Service Executive, Dublin

7. Atkins R (2010) 2010 AGS/BGS Clinical Practice Guideline: Prevention of Falls in Older Persons. American Geriatrics Society,

8. Nederlandse Vereniging voor Klinische Geriatrie (2017) Preventie van valincidenten bij ouderen. Richtlijn Database, Federatie van de Medisch Specialisten.

https://www.richtlijnendatabase.nl/richtlijn/preventie van valincidenten bij ouderen/startpagina - preventie van valincidenten.html. Accessed 16 August 20182018

9. Deandrea S, Lucenteforte E, Bravi F, Foschi R, La Vecchia C, Negri E (2010) Risk factors for falls in community-dwelling older people: a systematic review and meta-analysis. Epidemiology 21 (5):658668. doi:10.1097/EDE.0b013e3181e89905

10. Ambrose AF, Paul G, Hausdorff JM (2013) Risk factors for falls among older adults: a review of the literature. Maturitas 75 (1):51-61. doi:10.1016/j.maturitas.2013.02.009

11. Reinders I, van Schoor NM, Deeg DJH, Huisman M, Visser M (2017) Trends in lifestyle among three cohorts of adults aged 55-64 years in 1992/1993, 2002/2003 and 2012/2013. Eur J Public Health. doi:10.1093/eurpub/ckx173

12. Lv J, Liu Q, Ren Y, Gong T, Wang S, Li L (2011) Socio-demographic association of multiple modifiable lifestyle risk factors and their clustering in a representative urban population of adults: a cross-sectional study in Hangzhou, China. Int J Behav Nutr Phys Act 8:40. doi:10.1186/1479-5868-840

13. House JS, Lantz PM, Herd P (2005) Continuity and change in the social stratification of aging and health over the life course: evidence from a nationally representative longitudinal study from 1986 to 2001/2002 (Americans' Changing Lives Study). J Gerontol B Psychol Sci Soc Sci 60 Spec No 2:15-26 14. Mishra GD, Ball K, Dobson AJ, Byles JE (2004) Do socioeconomic gradients in women's health widen over time and with age? Soc Sci Med 58 (9):1585-1595. doi:10.1016/S0277-9536(03)00368-X 15. White AM, Tooth LR, Peeters GMEE (2018) Fall Risk Factors in Mid-Age Women: The Australian Longitudinal Study on Women's Health. Am J Prev Med 54 (1):51-63.

doi:10.1016/j.amepre.2017.10.009 
16. Kool B, Ameratunga S, Robinson E (2012) Association between prescription medications and falls at home among young and middle-aged adults. Inj Prev 18 (3):200-203. doi:10.1136/injuryprev2011-040202

17. Thornley S, Kool B, Marshall RJ, Ameratunga S (2014) Alcohol intake, marijuana use, and sleep deprivation on the risk of falls occurring at home among young and middle-aged adults: a casecrossover study. N Z Med J 127 (1406):32-38

18. Malmivaara A, Heliovaara M, Knekt P, Reunanen A, Aromaa A (1993) Risk factors for injurious falls leading to hospitalization or death in a cohort of 19,500 adults. Am J Epidemiol 138 (6):384-394 19. Franse CB, Rietjens JA, Burdorf A, van Grieken A, Korfage IJ, van der Heide A, Mattace Raso F, van Beeck $E$, Raat $H$ (2017) A prospective study on the variation in falling and fall risk among communitydwelling older citizens in 12 European countries. BMJ open 7 (6):e015827. doi:10.1136/bmjopen2017-015827

20. Lee C, Dobson AJ, Brown WJ, Bryson L, Byles J, Warner-Smith P, Young AF (2005) Cohort Profile: the Australian Longitudinal Study on Women's Health. Int J Epidemiol 34 (5):987-991. doi:10.1093/ije/dyi098

21. Dobson AJ, Hockey R, Brown WJ, Byles JE, Loxton DJ, McLaughlin D, Tooth LR, Mishra GD (2015) Cohort Profile Update: Australian Longitudinal Study on Women's Health. Int J Epidemiol 44 (5):1547,1547a-1547f. doi:10.1093/ije/dyv110

22. Huisman M, Poppelaars J, van der Horst M, Beekman AT, Brug J, van Tilburg TG, Deeg DJ (2011) Cohort profile: the longitudinal aging study amsterdam. Int J Epidemiol 40 (4):868-876. doi:10.1093/ije/dyq219

23. Kuh D, Pierce M, Adams J, Deanfield J, Ekelund U, Friberg P, Ghosh AK, Harwood N, Hughes A, Macfarlane PW, Mishra G, Pellerin D, Wong A, Stephen AM, Richards M, Hardy R (2011) Cohort Profile: Updating the cohort profile for the MRC National Survey of Health and Development: a new clinic-based data collection for ageing research. Int J Epidemiol 40 (1):e1-e9. doi:10.1093/ije/dyq231 24. Wadsworth M, Kuh D, Richards M, Hardy R (2006) Cohort Profile: The 1946 National Birth Cohort (MRC National Survey of Health and Development). Int J Epidemiol 35 (1):49-54. doi:10.1093/ije/dyi201

25. Kearney PM, Cronin H, O'Regan C, Kamiya Y, Savva GM, Whelan B, Kenny R (2011) Cohort profile: the Irish Longitudinal Study on Ageing. Int J Epidemiol 40 (4):877-884. doi:10.1093/ije/dyr116 26. Deandrea S, Bravi F, Turati F, Lucenteforte E, La Vecchia C, Negri E (2013) Risk factors for falls in older people in nursing homes and hospitals. A systematic review and meta-analysis. Arch Gerontol Geriatr 56 (3):407-415. doi:10.1016/j.archger.2012.12.006 
27. de Boer A, Geuskens GA, Bultmann U, Boot CRL, Wind H, Koppes LL, Frings-Dresen MHW (2018) Employment status transitions in employees with and without chronic disease in the Netherlands. International journal of public health 63 (6):713-722. doi:10.1007/s00038-018-1120-8

28. Demou E, Bhaskar A, Xu T, Mackay DF, Hunt K (2017) Health, lifestyle and employment beyond state-pension age. BMC Public Health 17 (1):971. doi:10.1186/s12889-017-4957-5

29. van Rijn RM, Robroek SJ, Brouwer S, Burdorf A (2014) Influence of poor health on exit from paid employment: a systematic review. Occup Environ Med 71 (4):295-301. doi:10.1136/oemed-2013101591

30. Ganz DA, Bao Y, Shekelle PG, Rubenstein LZ (2007) Will my patient fall? JAMA 297 (1):77-86. doi:10.1001/jama.297.1.77

31. Muir SW, Gopaul K, Montero Odasso MM (2012) The role of cognitive impairment in fall risk among older adults: a systematic review and meta-analysis. Age Ageing 41 (3):299-308. doi:10.1093/ageing/afs012

32. Kearney FC, Harwood RH, Gladman JR, Lincoln N, Masud T (2013) The relationship between executive function and falls and gait abnormalities in older adults: a systematic review. Dement Geriatr Cogn Disord 36 (1-2):20-35. doi:10.1159/000350031

33. van Schoor NM, Smit JH, Pluijm SM, Jonker C, Lips P (2002) Different cognitive functions in relation to falls among older persons. Immediate memory as an independent risk factor for falls. J Clin Epidemiol 55 (9):855-862

34. Anstey KJ, von Sanden C, Luszcz MA (2006) An 8-year prospective study of the relationship between cognitive performance and falling in very old adults. J Am Geriatr Soc 54 (8):1169-1176 35. Lord SR, Smith ST, Menant JC (2010) Vision and falls in older people: risk factors and intervention strategies. Clin Geriatr Med 26 (4):569-581. doi:10.1016/j.cger.2010.06.002

36. Saftari LN, Kwon OS (2018) Ageing vision and falls: a review. J Physiol Anthropol 37 (1):11. doi:10.1186/s40101-018-0170-1

37. Kulmala J, Viljanen A, Sipila S, Pajala S, Parssinen O, Kauppinen M, Koskenvuo M, Kaprio J, Rantanen T (2009) Poor vision accompanied with other sensory impairments as a predictor of falls in older women. Age Ageing 38 (2):162-167. doi:10.1093/ageing/afn228

38. Wilson SJ, Garner JC, Loprinzi PD (2016) The influence of multiple sensory impairments on functional balance and difficulty with falls among U.S. adults. Prev Med 87:41-46.

doi:10.1016/j.ypmed.2016.02.023

39. Tiedemann AC, Sherrington C, Lord SR (2007) Physical and psychological factors associated with stair negotiation performance in older people. J Gerontol A Biol Sci Med Sci 62 (11):1259-1265 
40. Menant JC, St George RJ, Fitzpatrick RC, Lord SR (2010) Impaired depth perception and restricted pitch head movement increase obstacle contacts when dual-tasking in older people. J Gerontol A Biol Sci Med Sci 65 (7):751-757. doi:10.1093/gerona/glq015

41. Cawthon PM, Harrison SL, Barrett-Connor E, Fink HA, Cauley JA, Lewis CE, Orwoll ES, Cummings SR (2006) Alcohol intake and its relationship with bone mineral density, falls, and fracture risk in older men. J Am Geriatr Soc 54 (11):1649-1657. doi:10.1111/j.1532-5415.2006.00912.x

42. Mukamal KJ, Mittleman MA, Longstreth WT, Jr., Newman AB, Fried LP, Siscovick DS (2004) Selfreported alcohol consumption and falls in older adults: cross-sectional and longitudinal analyses of the cardiovascular health study. J Am Geriatr Soc 52 (7):1174-1179. doi:10.1111/j.15325415.2004.52318.x

43. Peeters GM, van Schoor NM, Pluijm SM, Deeg DJ, Lips P (2010) Is there a U-shaped association between physical activity and falling in older persons? Osteoporos Int 21 (7):1189-1195. doi:10.1007/s00198-009-1053-4

44. Andre H, Moniz-Pereira V, Carnide F, Machado ML, Veloso A Does the prevalence of falls decrease with higher physical activity levels in the elderly? In: Congress of the European College of Sports Science (ECSS), Antalya, Turkey, 23-26 June 2010.

45. Pahor M, Guralnik JM, Ambrosius WT, Blair S, Bonds DE, Church TS, Espeland MA, Fielding RA, Gill TM, Groessl EJ, King AC, Kritchevsky SB, Manini TM, McDermott MM, Miller ME, Newman AB, Rejeski WJ, Sink KM, Williamson JD (2014) Effect of structured physical activity on prevention of major mobility disability in older adults: the LIFE study randomized clinical trial. JAMA 311 (23):23872396. doi:10.1001/jama.2014.5616

46. Pluijm SM, Smit JH, Tromp EA, Stel VS, Deeg DJ, Bouter LM, Lips P (2006) A risk profile for identifying community-dwelling elderly with a high risk of recurrent falling: results of a 3-year prospective study. Osteoporos Int 17 (3):417-425. doi:10.1007/s00198-005-0002-0 
Table 1. Sample characteristics for each cohort and at each data collection wave.

\begin{tabular}{|c|c|c|c|c|c|c|c|c|c|c|}
\hline \multirow[b]{2}{*}{ Year of data collection } & \multirow[b]{2}{*}{2004} & \multicolumn{2}{|c|}{$\begin{array}{l}\text { Australia } \\
\text { (ALSWH) }\end{array}$} & \multirow[b]{2}{*}{2013} & \multirow{2}{*}{$\begin{array}{c}\text { Netherlands } \\
\text { (LASA) } \\
2012\end{array}$} & \multicolumn{2}{|c|}{$\begin{array}{l}\text { Great Britain } \\
\text { (NSHD) }\end{array}$} & \multicolumn{3}{|c|}{$\begin{array}{l}\text { Ireland } \\
\text { (TILDA) }\end{array}$} \\
\hline & & 2007 & 2010 & & & 1999 & 2006-10 & 2010 & 2012 & 2014 \\
\hline $\mathrm{N}$ & 10641 & 10525 & 9887 & 4883 & 862 & 2987 & 2210 & 4663 & 3825 & 3035 \\
\hline $\operatorname{Age}^{1}$ & $55.0(1.5)$ & $58.0(1.5)$ & $61.1(1.5)$ & $63.1(0.8)$ & $59.7(2.8)$ & $53.5(0.2)$ & $63.4(1.1)$ & $56.7(4.3)$ & $57.6(3.9)$ & $58.6(3.4)$ \\
\hline Sex (\% women) & 100 & 100 & 100 & 100 & 51.6 & 50.9 & 52.1 & 55.5 & 56.2 & 57.3 \\
\hline Education (\% tertiary) & 35.0 & 35.3 & 36.1 & 38.9 & 32.1 & 9.9 & 11.3 & 34.1 & $\mathrm{n} / \mathrm{a}$ & 41.9 \\
\hline Married or partnered (\%) & 80.5 & 78.5 & 76.9 & 76.4 & 74.1 & 77.9 & 79.1 & 76.7 & 77.3 & 77.7 \\
\hline$\geq 2$ others in household (\%) & 27.2 & 18.7 & 15.1 & 15.3 & 19.1 & 44.3 & 16.8 & 47.2 & 48.0 & 46.8 \\
\hline Retired (\%) & $\mathrm{n} / \mathrm{a}$ & $\mathrm{n} / \mathrm{a}$ & $\mathrm{n} / \mathrm{a}$ & $\mathrm{n} / \mathrm{a}$ & 16.0 & $\mathrm{n} / \mathrm{a}$ & 61.7 & 13.0 & 14.3 & 15.0 \\
\hline Living in urban areas (\%) & 76.8 & 76.8 & 77.8 & 78.5 & 59.4 & $\mathrm{n} / \mathrm{a}$ & $\mathrm{n} / \mathrm{a}$ & 51.2 & 50.9 & 49.9 \\
\hline SRH (\% good-excellent) & 85.8 & 86.3 & 86.1 & 87.2 & 87.5 & $\mathrm{n} / \mathrm{a}$ & 86.1 & 85.3 & 85.7 & 86.1 \\
\hline$\geq 2$ chronic conditions (\%) & 2.5 & 3.5 & 4.4 & 5.2 & 6.4 & 3.1 & 10.1 & 4.5 & 2.9 & 3.3 \\
\hline Osteoarthritis (\%) & $\mathrm{n} / \mathrm{a}$ & 15.9 & 18.6 & 25.9 & 40.1 & $\mathrm{n} / \mathrm{a}$ & $\mathrm{n} / \mathrm{a}$ & 9.3 & 12.5 & 12.5 \\
\hline Rheumatoid arthritis (\%) & $\mathrm{n} / \mathrm{a}$ & 4.7 & 5.0 & 5.0 & 8.2 & $\mathrm{n} / \mathrm{a}$ & $\mathrm{n} / \mathrm{a}$ & 6.1 & 5.7 & 5.5 \\
\hline Cancer (\%) & 3.2 & 3.8 & 4.1 & 4.6 & 9.9 & 3.1 & 11.6 & 4.8 & 1.4 & 2.0 \\
\hline Diabetes (\%) & 4.6 & 6.7 & 7.9 & 8.4 & 7.7 & 2.9 & 8.0 & 5.6 & 5.5 & 5.8 \\
\hline Heart disease (\%) & 3.1 & 4.0 & 4.4 & 5.1 & 11.0 & 4.5 & 12.8 & 11.1 & 9.3 & 10.0 \\
\hline Hypertension (\%) & 20.7 & 28.0 & 30.5 & 32.7 & 28.3 & $\mathrm{n} / \mathrm{a}$ & 33.6 & 29.2 & 27.4 & 27.7 \\
\hline Lung disease (\%) & 13.4 & 14.1 & 15.1 & 16.9 & 10.2 & 19.0 & 18.8 & 11.6 & 10.3 & 10.6 \\
\hline Stroke (\%) & 0.5 & 4.0 & 1.0 & 0.8 & 2.1 & 0.8 & 1.7 & 0.8 & 0.8 & 0.2 \\
\hline Depression (\%) & 20.8 & 19.7 & 18.7 & 16.6 & 12.0 & 15.6 & 11.6 & 10.6 & 9.9 & 8.5 \\
\hline Anxiety (\%) & 25.8 & 19.5 & 17.9 & 16.4 & 23.3 & 27.8 & 25.2 & 28.7 & $\mathrm{n} / \mathrm{a}$ & 15.5 \\
\hline $\mathrm{N}^{0}$ medications $(0-6)^{1}$ & $\mathrm{n} / \mathrm{a}$ & $3[1-4]$ & $4[2-6]$ & $\mathrm{n} / \mathrm{a}$ & $1[0-3]$ & $0[0-2]$ & $2[0-4]$ & $1[0-3]$ & $1[0-3]$ & $1[0-3]$ \\
\hline Polypharmacy ${ }^{1}$ & $\mathrm{n} / \mathrm{a}$ & 22.7 & 40.2 & $\mathrm{n} / \mathrm{a}$ & 14.0 & 4.6 & 20.8 & 11.9 & 15.8 & 13.3 \\
\hline Benzodiazepine ${ }^{1}$ & $\mathrm{n} / \mathrm{a}$ & 4.2 & 4.0 & $\mathrm{n} / \mathrm{a}$ & 4.7 & 1.5 & 1.7 & 3.9 & 4.1 & 3.9 \\
\hline
\end{tabular}




\begin{tabular}{|c|c|c|c|c|c|c|c|c|c|c|}
\hline Immediate recall $(\%<11)$ & $\mathrm{n} / \mathrm{a}$ & $\mathrm{n} / \mathrm{a}$ & $\mathrm{n} / \mathrm{a}$ & $\mathrm{n} / \mathrm{a}$ & 4.5 & 4.3 & 3.2 & 2.2 & 1.0 & 1.0 \\
\hline Delayed recall $(\%<4)$ & $\mathrm{n} / \mathrm{a}$ & $\mathrm{n} / \mathrm{a}$ & $\mathrm{n} / \mathrm{a}$ & $\mathrm{n} / \mathrm{a}$ & 10.6 & 2.8 & 2.4 & 9.5 & 8.4 & 7.8 \\
\hline Verbal fluency $(0-62)^{1}$ & $\mathrm{n} / \mathrm{a}$ & $\mathrm{n} / \mathrm{a}$ & $\mathrm{n} / \mathrm{a}$ & $\mathrm{n} / \mathrm{a}$ & $22.5(5.9)$ & $\mathrm{n} / \mathrm{a}$ & $23.6(6.9)$ & $21.7(7.1)$ & $20.6(6.0)$ & $20.5(5.9)$ \\
\hline Grip strength - women $(\mathrm{kg})^{1}$ & $\mathrm{n} / \mathrm{a}$ & $\mathrm{n} / \mathrm{a}$ & $\mathrm{n} / \mathrm{a}$ & $\mathrm{n} / \mathrm{a}$ & $25.9(6.1)$ & $28.0(7.8)$ & $26.2(7.3)$ & $22.6(5.1)$ & $24.78(6.0)$ & $24.2(5.0)$ \\
\hline Grip strength - men $(\mathrm{kg})^{1}$ & $\mathrm{n} / \mathrm{a}$ & $\mathrm{n} / \mathrm{a}$ & $\mathrm{n} / \mathrm{a}$ & $\mathrm{n} / \mathrm{a}$ & $45.5(8.5)$ & $47.7(12.2)$ & $44.7(11.5)$ & $38.5(8.0)$ & $40.8(8.7)$ & 39.7 (7.9) \\
\hline Mobility (\% poor/unable) & $\mathrm{n} / \mathrm{a}$ & $\mathrm{n} / \mathrm{a}$ & $\mathrm{n} / \mathrm{a}$ & $\mathrm{n} / \mathrm{a}$ & 14.2 & $\mathrm{n} / \mathrm{a}$ & 26.8 & 12.6 & $\mathrm{n} / \mathrm{a}$ & 17.9 \\
\hline Use of a walking aid (\%) & $\mathrm{n} / \mathrm{a}$ & $\mathrm{n} / \mathrm{a}$ & $\mathrm{n} / \mathrm{a}$ & $\mathrm{n} / \mathrm{a}$ & 3.3 & $\mathrm{n} / \mathrm{a}$ & 1.4 & 0.4 & 0.4 & 0.2 \\
\hline Functional limitations $(\% \geq 1)$ & 48.8 & 51.0 & 53.8 & 56.0 & 29.2 & $\mathrm{n} / \mathrm{a}$ & 23.5 & 18.7 & 18.8 & 17.1 \\
\hline Diastolic Bp (per 10 mmHg) & $\mathrm{n} / \mathrm{a}$ & $\mathrm{n} / \mathrm{a}$ & $\mathrm{n} / \mathrm{a}$ & $\mathrm{n} / \mathrm{a}$ & $83.5(11.1)$ & $84.4(12.3)$ & $77.8(10.0)$ & $82.4(11.3)$ & $\mathrm{n} / \mathrm{a}$ & $80.7(10.5)$ \\
\hline Systolic Bp (per 10 mmHg) & $\mathrm{n} / \mathrm{a}$ & $\mathrm{n} / \mathrm{a}$ & $\mathrm{n} / \mathrm{a}$ & $\mathrm{n} / \mathrm{a}$ & $137.3(19.0)$ & $136.1(20.1)$ & $136.4(18.3)$ & $129.5(18.4)$ & $\mathrm{n} / \mathrm{a}$ & $127.1(17.2)$ \\
\hline Body mass index ${ }^{1}$ & $27.2(5.5)$ & $27.4(5.6)$ & $27.6(5.6)$ & $27.7(5.8)$ & $27.1(4.7)$ & $27.4(4.8)$ & $27.9(4.9)$ & $28.6(5.1)$ & $27.3(4.8)$ & $27.4(5.0)$ \\
\hline Waist circumference & $\mathrm{n} / \mathrm{a}$ & $\mathrm{n} / \mathrm{a}$ & $\mathrm{n} / \mathrm{a}$ & $\mathrm{n} / \mathrm{a}$ & $96.8(13.2)$ & $91.7(13.3)$ & $96.5(12.9)$ & $94.5(14.0)$ & $\mathrm{n} / \mathrm{a}$ & $95.6(14.1)$ \\
\hline Dizzy (\%) & $\mathrm{n} / \mathrm{a}$ & $\mathrm{n} / \mathrm{a}$ & 17.7 & 16.3 & 6.6 & 14.5 & 22.6 & $\mathrm{n} / \mathrm{a}$ & $\mathrm{n} / \mathrm{a}$ & $\mathrm{n} / \mathrm{a}$ \\
\hline Pain (\%) & 50.7 & 51.6 & 53.9 & 54.6 & 28.1 & $\mathrm{n} / \mathrm{a}$ & 23.6 & 35.2 & 33.6 & 34.0 \\
\hline Hearing problems (\%) & 17.9 & 20.0 & 20.5 & 22.8 & 7.1 & 17.2 & 23.8 & 11.7 & 12.3 & 12.8 \\
\hline $\begin{array}{l}\text { Vision problems (\% near } \\
\text { and/or far) }\end{array}$ & $\mathrm{n} / \mathrm{a}$ & $\mathrm{n} / \mathrm{a}$ & $\mathrm{n} / \mathrm{a}$ & $\mathrm{n} / \mathrm{a}$ & 21.0 & $\mathrm{n} / \mathrm{a}$ & 8.7 & 15.8 & $\mathrm{n} / \mathrm{a}$ & $\mathrm{n} / \mathrm{a}$ \\
\hline Sleeping problems (\% any) & 62.2 & 67.5 & 66.7 & 66.5 & 31.2 & $\mathrm{n} / \mathrm{a}$ & $\mathrm{n} / \mathrm{a}$ & 57.4 & 56.2 & 58.6 \\
\hline $\begin{array}{l}\text { Urinary incontinence (\%) } \\
\text { Level of alcohol intake (\%) }\end{array}$ & 45.6 & 46.0 & 46.5 & 59.0 & 16.7 & $\mathrm{n} / \mathrm{a}$ & 32.2 & 10.5 & 12.6 & 10.3 \\
\hline Low risk & 54.1 & 56.7 & 55.4 & 54.5 & 55.7 & 54.2 & 61.4 & 49.3 & 43.6 & 58.9 \\
\hline Never/rarely drinks & 39.2 & 37.0 & 37.9 & 39.1 & 14.2 & 27.2 & 15.5 & 30.7 & 27.1 & 26.7 \\
\hline Risky/high risk & 6.7 & 6.3 & 6.7 & 6.4 & 30.1 & 18.7 & 23.2 & 20.0 & 29.3 & 14.5 \\
\hline Smoking status (\%) & & & & & & & & & & \\
\hline Never smoked & 59.1 & 60.0 & 60.7 & 61.9 & 25.9 & 29.3 & 32.3 & 43.5 & 44.2 & 44.4 \\
\hline Ex-smoker & 27.4 & 29.0 & 30.4 & 30.0 & 55.9 & 47.5 & 56.4 & 35.0 & 36.6 & 39.5 \\
\hline Current smoker & 13.5 & 11.0 & 8.9 & 8.2 & 18.1 & 23.2 & 11.3 & 21.6 & 19.2 & 16.1 \\
\hline Level of physical activity (\%) & & & & & & & & & & \\
\hline
\end{tabular}




\begin{tabular}{l|cccc|c|cccccc} 
Inactive & 16.4 & 16.1 & 16.7 & 17.4 & 3.4 & n/a & 7.3 & 7.0 & 5.7 & 15.4 \\
Low & 25.4 & 22.7 & 23.4 & 21.0 & 16.8 & & 15.2 & 13.1 & 12.5 & 3.8 \\
High & 58.3 & 61.2 & 59.8 & 61.5 & 79.8 & & 77.4 & 80.0 & 81.7 & 80.8 \\
Faller (\%) & 22.1 & 31.6 & 30.3 & 26.1 & 25.1 & 17.4 & 18.3 & 17.6 & 18.6 \\
\hline
\end{tabular}

SRH Self-rated health

n/a Data not available, not reliably measured, or not possible to harmonise available variables in a comparable way to the other cohorts

${ }^{1}$ Presented are the mean (standard deviation)

${ }^{2}$ Presented are the median [interquartile range] 
Table 2. Cross-sectional associations between each of the risk factors and fall status in each of the cohorts and pooled across the cohorts

\begin{tabular}{|c|c|c|c|c|c|c|c|c|}
\hline & $\begin{array}{l}\text { ALSWH } \\
\text { Australia } \\
\text { OR (99\%) }\end{array}$ & $\begin{array}{l}\text { LASA } \\
\text { Netherlands } \\
\text { OR }(99 \%)\end{array}$ & $\begin{array}{l}\text { NSHD } \\
\text { Great Britain } \\
\text { OR }(99 \% \mathrm{Cl})\end{array}$ & $\begin{array}{l}\text { TILDA } \\
\text { Ireland } \\
\text { OR (99\%) }\end{array}$ & $\begin{array}{l}\text { Pooled } \\
\text { estimates } \\
\text { OR (99\%) }\end{array}$ & $\begin{array}{l}\mathrm{I}^{2}(\mathrm{p} \text {-value) for } \\
\text { heterogeneity } \\
\text { between } \\
\text { cohorts }\end{array}$ & $\begin{array}{l}\text { p-value for } \\
\text { interaction } \\
\text { with cohort }\end{array}$ & $\begin{array}{l}\text { p-value for } \\
\text { interaction } \\
\text { with sex }\end{array}$ \\
\hline \multicolumn{9}{|l|}{ Demographic factors } \\
\hline \multicolumn{9}{|l|}{ Age } \\
\hline $50-54$ years & 1 & $\mathrm{n} / \mathrm{a}$ & 1 & 1 & & $n / a^{3}$ & $n / a^{3}$ & 0.005 \\
\hline $55-59$ years & 1.43 (1.29-1.59) & 1 & $\mathrm{n} / \mathrm{a}$ & $1.22(1.03-1.43)$ & & & & \\
\hline $60-64$ years & $1.56(1.41-1.74)$ & $1.14(0.76-1.71)$ & $1.05(0.87-1.27)$ & $1.36(1.15-1.60)$ & & & & \\
\hline Sex & & & & & & $84.5 \%(0.002)$ & 0.002 & $\mathrm{n} / \mathrm{a}$ \\
\hline Male & $\mathrm{n} / \mathrm{a}$ & 1 & 1 & 1 & & & & \\
\hline Female & & $1.27(0.84-1.90)$ & $1.90(1.57-2.31)$ & $1.23(1.08-1.39)$ & & & & \\
\hline Education & & & & & & $41.1 \%(0.10)$ & 0.59 & 0.78 \\
\hline Tertiary & 1 & 1 & 1 & 1 & 1 & & & \\
\hline Secondary & $0.92(0.86-0.99)$ & $1.10(0.70-1.73)$ & $1.19(0.83-1.69)$ & $0.88(0.74-1.04)$ & $0.94(0.88-1.01)$ & & & \\
\hline Primary/none & $1.07(0.98-1.17)$ & $0.92(0.43-1.96)$ & $1.05(0.72-1.52)$ & $1.05(0.84-1.30)$ & $1.06(0.97-1.15)$ & & & \\
\hline Marital status & & & & & & $40.3 \%(0.05)$ & 0.04 & 0.03 \\
\hline Married & 1 & 1 & 1 & 1 & 1 & & & \\
\hline Registered partnership ${ }^{1}$ & $1.04(0.90-1.19)$ & $0.94(0.28-3.21)$ & $\mathrm{n} / \mathrm{a}$ & 1.44 (1.04-1.99) & $1.13(0.98-1.29)$ & & & \\
\hline Single (never married) & $1.14(0.95-1.37)$ & $1.19(0.63-2.25)$ & $1.78(1.21-2.64)$ & $1.20(0.96-1.49)$ & $1.21(1.04-1.38)$ & & & \\
\hline Separated/divorced & $1.29(1.18-1.41)$ & $1.05(0.52-2.14)$ & $1.46(1.11-1.92)$ & $1.74(1.43-2.11)$ & $1.40(1.29-1.51)$ & & & \\
\hline Widowed & $1.18(1.03-1.35)$ & $1.47(0.62-3.49)$ & $1.07(0.67-1.72)$ & $1.06(0.78-1.43)$ & 1.15 (1.01-1.29) & & & \\
\hline \multicolumn{2}{|c|}{$\mathrm{N}^{\circ}$ other people in household } & & & & & $0 \%(0.60)$ & 0.71 & 0.009 \\
\hline 0 & 1 & 1 & 1 & 1 & 1 & & & \\
\hline 1 & $0.77(0.71-0.84)$ & $1.02(0.60-1.72)$ & $0.67(0.50-0.90)$ & $0.76(0.63-0.91)$ & $0.92(0.54-1.30)$ & & & \\
\hline 2 & $0.76(0.68-0.85)$ & $0.62(0.27-1.44)$ & $0.65(0.46-0.92)$ & $0.79(0.65-0.97)$ & $0.66(0.26-1.05)$ & & & \\
\hline $3+$ & $0.75(0.65-0.87)$ & $0.73(0.28-1.89)$ & $0.71(0.48-1.03)$ & $0.69(0.56-0.85)$ & $0.71(0.17-1.26)$ & & & \\
\hline Retirement status & & & & & & $62.6 \%(0.07)$ & 0.37 & 0.55 \\
\hline Not retired & $\mathrm{n} / \mathrm{a}$ & 1 & 1 & 1 & 1 & & & \\
\hline
\end{tabular}




\begin{tabular}{|c|c|c|c|c|c|c|c|c|}
\hline Retired & & 0.77 (0.41-1.45) & $1.58(1.13-2.22)$ & $0.98(0.82-1.18)$ & 1.05 (0.89-1.22) & & & \\
\hline Urbanisation grade & & & & & & $94.5 \%(<0.001)$ & $<0.001$ & 0.20 \\
\hline Urban & 1 & 1 & $\mathrm{n} / \mathrm{a}$ & 1 & & & & \\
\hline Rural/remote & $1.11(1.03-1.19)$ & $1.08(0.72-1.63)$ & & $0.74(0.65-0.84)$ & & & & \\
\hline \multicolumn{9}{|l|}{ Health factors } \\
\hline Self-rated health & & & & & & $96.0 \%(<0.001)$ & 0.03 & 0.30 \\
\hline Excellent & 1 & 1 & 1 & 1 & 1 & & & \\
\hline Very good & $1.16(1.03-1.30)$ & $1.14(0.63-2.06)$ & $1.20(0.71-2.02)$ & $1.07(0.88-1.30)$ & 1.14 (1.03-1.25) & & & \\
\hline Good & 1.67 (1.49-1.88) & $0.90(0.44-1.84)$ & $1.49(0.88-2.53)$ & $1.42(1.17-1.72)$ & 1.59 (1.44-1.75) & & & \\
\hline Fair & $2.60(2.28-2.96)$ & 0.80 (0.34-1.89) & $2.34(1.28-4.28)$ & $2.11(1.69-2.65)$ & $2.45(2.17-2.72)$ & & & \\
\hline Poor & $3.18(2.49-4.06)$ & 3.27 (0.92-11.5) & $5.19(2.04-13.2)$ & $2.85(2.04-4.00)$ & 3.19 (2.54-3.84) & & & \\
\hline $\mathrm{N}^{\circ}$ chronic conditions & & & & & & $87.7 \%(<0.001)$ & 0.02 & 0.004 \\
\hline 0 & 1 & 1 & 1 & 1 & 1 & & & \\
\hline 1 & $1.40(1.30-1.50)$ & $0.97(0.60-1.58)$ & $1.37(1.10-1.71)$ & $1.26(1.09-1.46)$ & $1.36(1.28-1.44)$ & & & \\
\hline $2+$ & $2.03(1.75-2.36)$ & $1.66(0.77-3.57)$ & $1.95(1.33-2.86)$ & $1.64(1.22-2.20)$ & 1.93 (1.69-2.17) & & & \\
\hline Osteoarthritis ${ }^{2}$ & $1.74(1.60-1.90)$ & $1.37(0.90-2.08)$ & $\mathrm{n} / \mathrm{a}$ & $1.42(1.18-1.71)$ & $1.63(1.50-1.76)$ & $61.5 \%(0.07)$ & 0.04 & 0.92 \\
\hline Rheumatoid arthritis ${ }^{2}$ & $1.72(1.47-2.00)$ & 1.35 (0.67-2.69) & $\mathrm{n} / \mathrm{a}$ & $1.50(1.18-1.91)$ & $1.64(1.43-1.86)$ & $0 \%(0.54)$ & 0.34 & 0.97 \\
\hline Cancer $^{2}$ & $1.13(0.97-1.32)$ & 1.01 (0.51-1.99) & $1.07(0.73-1.56)$ & $1.09(0.76-1.56)$ & $1.11(0.96-1.27)$ & $0 \%(0.98)$ & 0.59 & 0.76 \\
\hline Diabetes $^{2}$ & $1.46(1.30-1.64)$ & $1.13(0.54-2.38)$ & $1.43(0.95-2.14)$ & $1.27(0.99-1.64)$ & $1.41(1.26-1.56)$ & $0 \%(0.70)$ & 0.18 & 0.03 \\
\hline Heart disease ${ }^{2}$ & 1.78 (1.54-2.05) & $1.28(0.68-2.40)$ & $1.46(1.04-2.05)$ & $1.30(1.08-1.58)$ & $1.64(1.45-1.82)$ & $67.8 \%(0.03)$ & $<0.001$ & $<0.001$ \\
\hline Hypertension ${ }^{2}$ & $1.29(1.20-1.37)$ & $1.43(0.92-2.21)$ & $1.07(0.79-1.44)$ & $1.06(0.92-1.22)$ & $1.23(1.16-1.30)$ & $63.2 \%(0.03)$ & $<0.001$ & 0.62 \\
\hline Lung disease ${ }^{2}$ & $1.53(1.41-1.66)$ & $1.29(0.68-2.44)$ & $1.54(1.23-1.94)$ & $1.38(1.15-1.66)$ & 1.48 (1.37-1.59) & $0 \%(0.67)$ & 0.22 & 0.17 \\
\hline Stroke ${ }^{2}$ & $2.20(1.78-2.72)$ & $0.59(0.11-3.03)$ & $2.22(1.05-4.71)$ & $1.91(1.00-3.63)$ & $2.11(1.65-2.57)$ & $32.0 \%(0.22)$ & 0.43 & 0.17 \\
\hline Depression ${ }^{2}$ & $1.93(1.80-2.08)$ & $1.44(0.79-2.62)$ & $1.81(1.41-2.32)$ & $1.85(1.54-2.23)$ & $1.89(1.76-2.02)$ & $0 \%(0.71)$ & 0.47 & 0.59 \\
\hline Anxiety ${ }^{2}$ & $1.61(1.50-1.73)$ & $1.37(0.85-2.18)$ & $1.20(0.95-1.52)$ & $1.24(1.02-1.51)$ & & $75.6 \%(<0.006)$ & $<0.001$ & 0.11 \\
\hline $\mathrm{N}^{\circ}$ medications $(0-6)$ & $1.13(1.10-1.15)$ & $1.06(0.96-1.17)$ & $1.15(1.09-121)$ & $1.12(1.09-1.16)$ & $1.13(1.11-1.15)$ & $0 \%(0.50)$ & 0.72 & 0.18 \\
\hline Polypharmacy² & $1.54(1.41-1.68)$ & $1.27(0.72-2.22)$ & $1.99(1.52-2.62)$ & $1.73(1.47-2.03)$ & $1.66(1.52-1.80)$ & $47.4 \%(0.13)$ & 0.01 & 0.70 \\
\hline Benzodiazepine $^{2}$ & $1.68(1.38-2.04)$ & $1.77(0.74-4.23)$ & $2.39(1.29-4.43)$ & $1.91(1.46-2.51)$ & $1.86(1.53-2.19)$ & $0 \%(0.65)$ & 0.26 & 0.19 \\
\hline Immediate recall & & & & & & $0 \%(0.68)$ & 0.70 & 0.35 \\
\hline
\end{tabular}




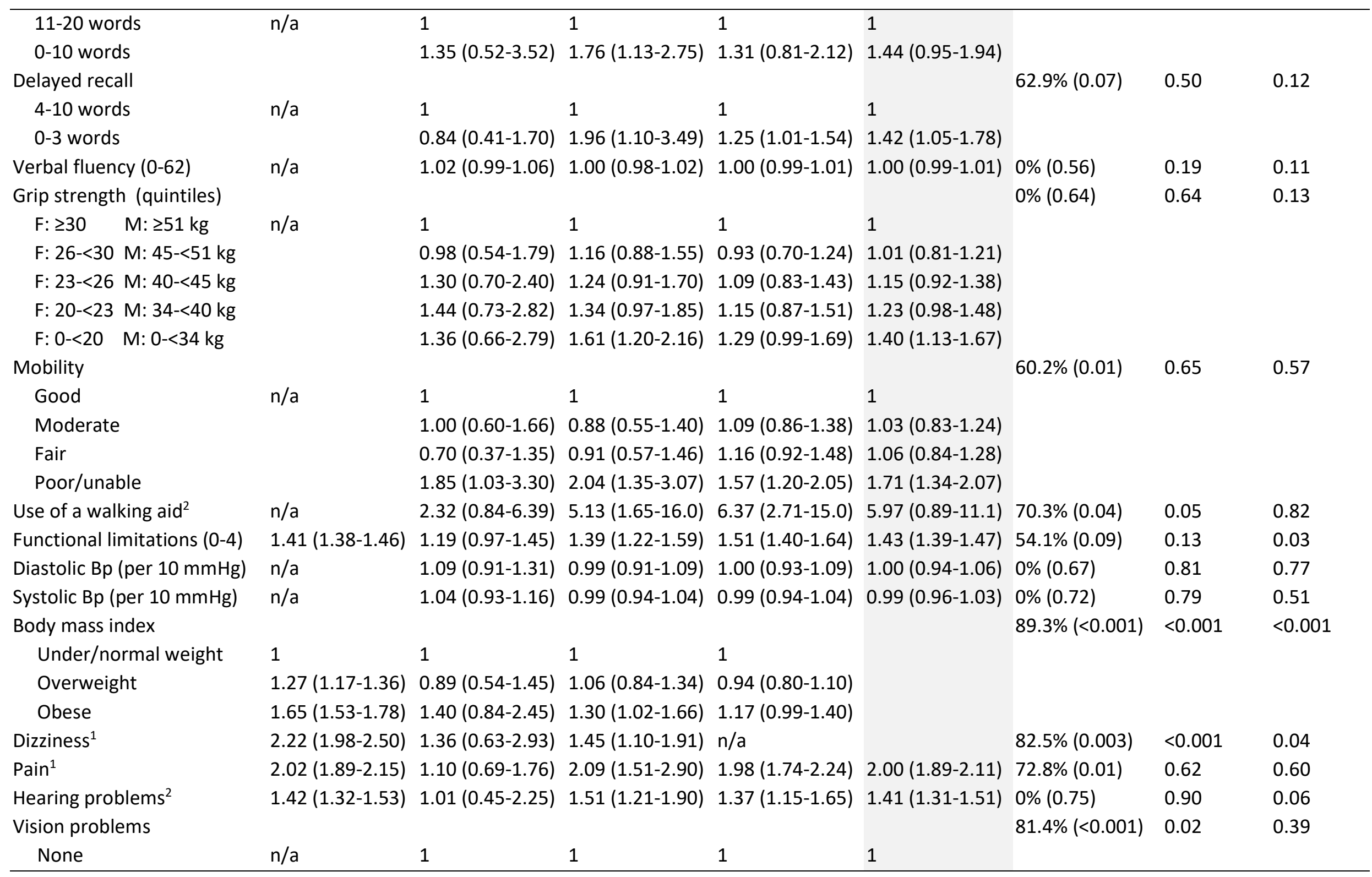




\begin{tabular}{|c|c|c|c|c|c|c|c|c|}
\hline Near only & & $1.09(0.65-1.81)$ & $2.41(1.25-4.63)$ & $0.93(0.64-1.34)$ & $1.37(0.84-1.90)$ & & & \\
\hline Far only & & $4.63(0.44-48.5)$ & $1.46(0.74-2.88)$ & $1.38(0.89-2.14)$ & $1.77(0-4.49)$ & & & \\
\hline Both near and far & & $5.89(0.65-53.5)$ & $3.43(1.29-9.12)$ & $1.59(0.94-2.73)$ & $2.60(0-5.80)$ & & & \\
\hline \multicolumn{9}{|l|}{ Sleeping problems } \\
\hline None & 1 & 1 & $\mathrm{n} / \mathrm{a}$ & 1 & & $83.6 \%(<0.001)$ & $<0.001$ & 0.09 \\
\hline Waking too early & $1.34(1.24-1.45)$ & $1.41(0.81-2.47)$ & & $1.28(1.09-1.52)$ & & & & \\
\hline Difficulty falling asleep & $1.50(1.35-1.66)$ & $0.86(0.35-2.10)$ & & $1.29(1.03-1.62)$ & & & & \\
\hline Both & $1.96(1.80-2.14)$ & $1.37(0.64-2.92)$ & & $1.58(1.36-1.85)$ & & & & \\
\hline Urinary incontinence ${ }^{2}$ & $1.53(1.44-1.63)$ & $1.62(0.95-2.78)$ & $1.68(1.22-2.31)$ & $2.09(1.75-2.49)$ & & $76.9 \%(0.005)$ & $<0.001$ & $<0.001$ \\
\hline \multicolumn{9}{|l|}{ Lifestyle factors } \\
\hline Level of alcohol intake & & & & & & $0 \%(0.73)$ & 0.40 & 0.05 \\
\hline Low risk & 1 & 1 & 1 & 1 & 1 & & & \\
\hline Never/rarely drinks & 1.09 (1.03-1.17) & $0.79(0.42-1.49)$ & $1.24(0.97-1.57)$ & $1.00(0.85-1.19)$ & $1.08(1.02-1.15)$ & & & \\
\hline Risky/high risk & $1.12(0.99-1.27)$ & $1.10(0.69-1.74)$ & $1.03(0.78-1.37)$ & $1.18(0.98-1.42)$ & $1.12(1.01-1.23)$ & & & \\
\hline Smoking status & & & & & & $0 \%(0.93)$ & 0.78 & 0.15 \\
\hline Never smoked & 1 & 1 & 1 & 1 & 1 & & & \\
\hline Ex-smoker & $1.14(1.06-1.22)$ & $1.36(0.82-2.24)$ & $1.12(0.90-1.39)$ & $1.08(0.94-1.24)$ & $1.13(1.06-1.20)$ & & & \\
\hline Current smoker & $1.07(0.97-1.18)$ & $1.47(0.78-2.77)$ & $1.05(0.79-1.41)$ & $1.11(0.94-1.32)$ & $1.08(0.99-1.17)$ & & & \\
\hline Level of physical activity & & & & & & $69.2 \%(0.002)$ & 0.36 & 0.93 \\
\hline High & 1 & 1 & 1 & 1 & 1 & & & \\
\hline Low & $1.05(0.97-1.13)$ & $1.21(0.71-2.05)$ & $1.34(0.91-1.96)$ & $0.94(0.76-1.17)$ & $1.04(0.97-1.12)$ & & & \\
\hline Inactive & $1.33(1.22-1.45)$ & $0.66(0.18-2.40)$ & $1.29(0.77-2.19)$ & $1.26(1.00-1.59)$ & $1.30(1.19-1.41)$ & & & \\
\hline \multicolumn{9}{|c|}{ OR odds ratio; 99\% $\mathrm{Cl} 99 \%$ confidence interval; F female; M male } \\
\hline \multicolumn{9}{|c|}{ All models were adjusted for age and sex. } \\
\hline \multicolumn{9}{|c|}{${ }^{1}$ Registered partnership may also include defacto relationships. } \\
\hline
\end{tabular}


Table 3. Prospective associations between each of the risk factors and fall status in three cohorts.

\begin{tabular}{|c|c|c|c|c|c|c|}
\hline & $\begin{array}{l}\text { ALSWH } \\
\text { Australia } \\
\text { OR (99\%) } \\
\end{array}$ & $\begin{array}{l}\text { NSHD } \\
\text { Great Britain } \\
\text { OR }(99 \% \mathrm{Cl}) \\
\end{array}$ & $\begin{array}{l}\text { TILDA } \\
\text { Ireland } \\
\text { OR (99\%) } \\
\end{array}$ & $\begin{array}{l}\mathrm{I}^{2}(\mathrm{p} \text {-value) for } \\
\text { heterogeneity } \\
\text { between cohorts }\end{array}$ & $\begin{array}{l}\text { p-value for } \\
\text { interaction with } \\
\text { cohort }\end{array}$ & $\begin{array}{l}\text { p-value for } \\
\text { interaction with } \\
\text { sex }\end{array}$ \\
\hline \multicolumn{7}{|l|}{ Demographic factors } \\
\hline \multicolumn{7}{|l|}{ Age } \\
\hline 50-54 years & 1 & $\mathrm{n} / \mathrm{a}$ & 1 & $80.6 \%(0.001)$ & $<0.001$ & 0.02 \\
\hline $55-59$ years & $0.99(0.90-1.09)$ & & $1.19(0.99-1.43)$ & & & \\
\hline $60-64$ years & $0.89(0.80-0.99)$ & & $1.34(1.11-1.62)$ & & & \\
\hline Sex & & & & $86.0 \%(0.008)$ & $<0.001$ & $\mathrm{n} / \mathrm{a}$ \\
\hline Male & $\mathrm{n} / \mathrm{a}$ & 1 & 1 & & & \\
\hline Female & & $1.92(1.42-2.60)$ & $1.16(1.00-1.35)$ & & & \\
\hline Education & & & & $55.7 \%(0.05)$ & 0.94 & 0.24 \\
\hline Tertiary & 1 & 1 & 1 & & & \\
\hline Secondary & $0.93(0.86-1.00)$ & $1.47(0.84-2.59)$ & $0.88(0.70-1.10)$ & & & \\
\hline Primary/none & $1.09(0.99-1.21)$ & $1.16(0.64-2.11)$ & $1.06(0.80-1.39)$ & & & \\
\hline Marital status & & & & $39.5 \%(0.09)$ & 0.01 & 0.02 \\
\hline Married & 1 & 1 & 1 & & & \\
\hline Registered partnership & $1.11(0.96-1.29)$ & $\mathrm{n} / \mathrm{a}$ & $1.28(0.85-1.92)$ & & & \\
\hline Single (never married) & $1.24(1.01-1.53)$ & $2.19(1.19-4.04)$ & $1.28(0.99-1.66)$ & & & \\
\hline Separated/divorced & $1.22(1.11-1.35)$ & $1.30(0.84-2.01)$ & $1.80(1.43-2.27)$ & & & \\
\hline Widowed & $1.23(1.05-1.44)$ & $0.48(0.16-1.48)$ & $1.22(0.86-1.71)$ & & & \\
\hline $\mathrm{N}^{\circ}$ others in the household & & & & $0 \%(0.52)$ & 0.006 & 0.58 \\
\hline 0 & 1 & 1 & 1 & & & \\
\hline 1 & $0.80(0.72-0.88)$ & $0.57(0.35-0.91)$ & $0.74(0.59-0.92)$ & & & \\
\hline 2 & $0.81(0.71-0.91)$ & $0.62(0.37-1.04)$ & $0.77(0.60-0.97)$ & & & \\
\hline $3+$ & $0.81(0.69-0.95)$ & $0.53(0.31-0.91)$ & $0.59(0.47-0.75)$ & & & \\
\hline Retirement status & & & & $4.3 \%(0.31)$ & 0.52 & 0.99 \\
\hline Not retired & $\mathrm{n} / \mathrm{a}$ & $\mathrm{n} / \mathrm{a}$ & 1 & & & \\
\hline
\end{tabular}


Retired

Urbanisation grade

\begin{tabular}{lll} 
Urban & 1 & n/a \\
Rural/remote & $1.13(1.04-1.22)$ & \\
\hline
\end{tabular}

\begin{tabular}{l}
\hline Health factors \\
\hline Self-rated health \\
Excellent \\
Very good \\
Good \\
Fair \\
Poor \\
$\mathrm{N}^{\circ}$ chronic conditions \\
0 \\
1 \\
$2+$
\end{tabular}

Osteoarthritis $^{1}$

Rheumatoid arthritis ${ }^{1}$

Cancer $^{1}$

Diabetes $^{1}$

Heart disease ${ }^{1}$

Hypertension $^{1}$

Lung disease ${ }^{1}$

Stroke ${ }^{1}$

Depression $^{1}$

Anxiety $^{1}$

$\mathrm{N}^{\circ}$ medications (0-6)

Polypharmacy ${ }^{1}$

Benzodiazepine $^{1}$

Immediate recall

$1.27(1.18-1.38) \quad$ n/a
$1.02(0.82-1.27)$

$97.4 \%(<0.001) \quad<0.001$

0.40

1

$0.71(0.61-0.83)$

$97.4 \%(<0.001) \quad 0.007 \quad 0.23$

1

$1.23(0.98-1.55)$

1.51 (1.20-1.89)

$1.99(1.52-2.62)$

$3.02(2.02-4.51)$

$\begin{array}{lll}92.3 \%(<0.001) & 0.04 & 0.03\end{array}$

1

$1.33(1.23-1.45) \quad 1.16(0.82-1.66) \quad 1.21(1.02-1.44)$

$2.20(1.84-2.64) \quad 1.38(0.52-3.67) \quad 1.61(1.13-2.28)$

$1.72(1.55-1.92) \quad \mathrm{n} / \mathrm{a} \quad 1.33(1.06-1.67)$

$1.73(1.43-2.09) \quad \mathrm{n} / \mathrm{a} \quad 1.56(1.18-2.07)$

$1.14(0.94-1.37) \quad 1.61(0.74-3.52) \quad 1.16(0.78-1.72)$

$1.49(1.30-1.71) \quad 0.67(0.19-2.41) \quad 1.22(0.90-1.66)$

$1.85(1.56-2.19) \quad 1.77(0.89-3.51) \quad 1.25(0.99-1.57)$

$1.05(0.89-1.24)$

$1.42(1.29-1.56) \quad 0.99(0.67-1.47) \quad 1.30(1.04-1.62)$

$1.79(1.40-2.28) \quad 3.57(0.65-19.7) \quad 1.60(0.77-3.34)$

$1.83(1.69-1.99) \quad 1.24(0.83-1.86) \quad 1.75(1.40-2.19)$

$2.26(2.07-2.46) \quad 1.47(1.03-2.10) \quad 1.12(0.85-1.47)$

$1.12(1.09-1.14) \quad 1.11(1.00-1.23) \quad 1.09(1.05-1.14)$

$1.52(1.38-1.67) \quad 1.98(1.01-3.86) \quad 1.54(1.26-1.89)$

$1.52(1.22-1.89) \quad 2.17(0.68-6.95) \quad 1.59(1.13-2.24)$

0.17

$0 \%(0.55) \quad 0.56$

$0 \%(0.79) \quad 0.59$

$39.8 \%(0.19) \quad 0.18$

$81.2 \%(0.005) \quad 0.002$

$78.2 \%(0.03) \quad 0.05$

$52.6 \%(0.12) \quad 0.11$

$0 \%(0.84) \quad 0.97$

$84.6 \%(<0.001) \quad 0.15$

$93.8 \%(<0.001) \quad<0.001$

$0 \%(0.50) \quad 0.93$

$0 \%(0.71) \quad 0.29$

$0 \%(0.85) \quad 0.68$

0.68
0.87

0.03

$0 \%(0.78)$

0.20

$<0.001$

0.51

0.003

0.64

0.09

0.52

0.44

0.05

0.73

0.62

0.52

0.37 


\begin{tabular}{|c|c|c|c|c|c|c|}
\hline $11-20$ words & $\mathrm{n} / \mathrm{a}$ & 1 & 1 & & & \\
\hline $0-10$ words & & $1.30(0.56-2.98)$ & $1.10(0.62-1.95)$ & & & \\
\hline Delayed recall & & & & $0 \%(0.47)$ & 0.28 & 0.89 \\
\hline 4-10 words & $\mathrm{n} / \mathrm{a}$ & 1 & 1 & & & \\
\hline $0-3$ words & & $0.77(0.19-3.19)$ & $1.25(0.97-1.61)$ & & & \\
\hline Verbal fluency (0-62) & $\mathrm{n} / \mathrm{a}$ & $1.01(0.98-1.03)$ & $1.00(0.99-1.01)$ & $0 \%(0.46)$ & 0.37 & 0.004 \\
\hline Grip strength (quintiles) & & & & $5.2 \%(0.39)$ & 0.25 & 0.22 \\
\hline $\mathrm{F}: \geq 30 \quad \mathrm{M}: \geq 51 \mathrm{~kg}$ & $\mathrm{n} / \mathrm{a}$ & 1 & 1 & & & \\
\hline $\mathrm{F}: 26-<30 \mathrm{M}: 45-<51 \mathrm{~kg}$ & & $1.06(0.72-1.57)$ & $1.30(0.94-1.83)$ & & & \\
\hline $\mathrm{F}: 23-<26 \mathrm{M}: 40-<45 \mathrm{~kg}$ & & $0.77(0.47-1.27)$ & $1.35(0.97-1.87)$ & & & \\
\hline $\mathrm{F}: 20-<23 \mathrm{M}: 34-<40 \mathrm{~kg}$ & & $1.04(0.62-1.75)$ & $1.26(0.90-1.75)$ & & & \\
\hline $\mathrm{F}: 0-<20 \quad \mathrm{M}: 0-<34 \mathrm{~kg}$ & & $1.06(0.66-1.71)$ & $1.35(0.98-1.87)$ & & & \\
\hline Mobility & & & & $\mathrm{n} / \mathrm{a}$ & $\mathrm{n} / \mathrm{a}$ & 0.55 \\
\hline Good & $\mathrm{n} / \mathrm{a}$ & $\mathrm{n} / \mathrm{a}$ & 1 & & & \\
\hline Moderate & & & $1.06(0.79-1.42)$ & & & \\
\hline Fair & & & $1.13(0.83-1.54)$ & & & \\
\hline Poor/unable & & & $1.39(0.97-2.01)$ & & & \\
\hline Use of a walking aid ${ }^{1}$ & $\mathrm{n} / \mathrm{a}$ & $\mathrm{n} / \mathrm{a}$ & $6.92(2.53-18.9)$ & $\mathrm{n} / \mathrm{a}$ & $\mathrm{n} / \mathrm{a}$ & 0.38 \\
\hline Functional limitations (0-4) & 1.39 (1.34-1.43) & $\mathrm{n} / \mathrm{a}$ & $1.48(1.35-1.63)$ & $42.1 \%(0.19)$ & 0.03 & 0.01 \\
\hline Diastolic Bp (per 10 mmHg) & $\mathrm{n} / \mathrm{a}$ & $0.96(0.85-1.09)$ & $1.00(0.90-1.11)$ & $0 \%(0.62)$ & 0.14 & 0.81 \\
\hline Systolic Bp (per 10 mmHg) & $\mathrm{n} / \mathrm{a}$ & $0.97(0.90-1.05)$ & $0.98(0.92-1.05)$ & $0 \%(0.84)$ & 0.20 & 0.50 \\
\hline Body mass index & & & & $88.9 \%(<0.001)$ & $<0.001$ & 0.34 \\
\hline Under/normal weight & 1 & 1 & 1 & & & \\
\hline Overweight & $1.23(1.14-1.34)$ & $0.98(0.70-1.37)$ & $0.98(0.80-1.20)$ & & & \\
\hline Obese & $1.66(1.52-1.81)$ & $1.04(0.70-1.55)$ & $1.17(0.94-1.45)$ & & & \\
\hline Dizziness $^{1}$ & $1.91(1.63-2.23)$ & $0.99(0.55-1.80)$ & $\mathrm{n} / \mathrm{a}$ & $86.0 \%(0.007)$ & 0.005 & $\mathrm{n} / \mathrm{a}$ \\
\hline Pain $^{1}$ & 1.80 (1.68-1.93) & $\mathrm{n} / \mathrm{a}$ & 1.85 (1.59-2.16) & $0 \%(0.75)$ & 0.52 & 0.62 \\
\hline Hearing problems ${ }^{1}$ & $1.44(1.32-1.56)$ & $1.35(0.92-1.97)$ & 1.43 (1.15-1.77) & $0 \%(0.95)$ & 0.75 & 0.32 \\
\hline
\end{tabular}




\begin{tabular}{|c|c|c|c|c|c|c|}
\hline None & $\mathrm{n} / \mathrm{a}$ & $\mathrm{n} / \mathrm{a}$ & 1 & $\mathrm{n} / \mathrm{a}$ & $\mathrm{n} / \mathrm{a}$ & 0.25 \\
\hline Near only & & & $0.93(0.64-1.34)$ & & & \\
\hline Far only & & & $1.38(0.89-2.14)$ & & & \\
\hline Both near and far & & & $1.60(0.94-2.73)$ & & & \\
\hline Sleeping problems & & & & $80.5 \%(<0.001)$ & 0.04 & 0.18 \\
\hline None & 1 & $\mathrm{n} / \mathrm{a}$ & 1 & & & \\
\hline Waking too early & $1.29(1.18-1.40)$ & & $1.34(1.11-1.63)$ & & & \\
\hline Difficulty falling asleep & $1.41(1.25-1.58)$ & & $1.22(0.93-1.61)$ & & & \\
\hline Both & $1.78(1.62-1.97)$ & & $1.53(1.27-1.84)$ & & & \\
\hline Urinary incontinence $^{1}$ & $1.46(1.36-1.56)$ & $1.38(0.97-1.95)$ & $1.99(1.61-2.45)$ & $77.8 \%(0.01)$ & $<0.001$ & 0.08 \\
\hline \multicolumn{7}{|l|}{ Lifestyle factors } \\
\hline Level of alcohol intake & & & & $0 \%(0.56)$ & 0.15 & 0.04 \\
\hline Low risk & 1 & 1 & 1 & & & \\
\hline Never/rarely drinks & $1.12(1.04-1.20)$ & $1.01(0.71-1.45)$ & $0.94(0.77-1.15)$ & & & \\
\hline Risky/high risk & $1.15(1.00-1.32)$ & $1.23(0.80-1.88)$ & $1.08(0.88-1.34)$ & & & \\
\hline Smoking status & & & & $0 \%(0.95)$ & 0.53 & 0.05 \\
\hline Never smoked & 1 & 1 & 1 & & & \\
\hline Ex-smoker & $1.12(1.03-1.20)$ & $1.11(0.79-1.55)$ & $1.08(0.92-1.28)$ & & & \\
\hline Current smoker & $1.05(0.94-1.17)$ & $1.10(0.72-1.69)$ & $1.15(0.95-1.41)$ & & & \\
\hline Level of physical activity & & & & $69.2 \%(0.02)$ & 0.05 & 0.74 \\
\hline High & 1 & $\mathrm{n} / \mathrm{a}$ & 1 & & & \\
\hline Low & $1.34(0.91-1.96)$ & & $0.94(0.76-1.17)$ & & & \\
\hline Inactive & $1.29(0.77-2.19)$ & & $1.26(1.00-1.59)$ & & & \\
\hline
\end{tabular}

OR odds ratio; $99 \% \mathrm{Cl} 99 \%$ confidence interval; $\mathrm{F}$ female; $\mathrm{M}$ male

All models were adjusted for age and sex.

${ }^{1}$ Registered partnership may also include defacto relationships.

${ }^{2}$ Not having the condition or limitation was defined as the reference category.

${ }^{3} I^{2}$ cannot be estimated when the reference category differs between cohorts. 
Table 4. Pooled estimates of between each of the risk factors ${ }^{1}$ and fall status, seperately for women and men

\begin{tabular}{|c|c|c|c|c|}
\hline & \multicolumn{2}{|c|}{ Cross-sectional associations } & \multicolumn{2}{|c|}{ Prospective associations } \\
\hline & Female & Male & Female & Male \\
\hline & OR $(99 \%)$ & OR (99\%) & OR $(99 \%)$ & OR (99\%) \\
\hline \multicolumn{5}{|c|}{$\mathrm{N}^{\circ}$ other people in household } \\
\hline 0 & 1 & 1 & - & - \\
\hline 1 & $0.78(0.73-0.84)$ & $0.70(0.55-0.88)$ & & \\
\hline 2 & $0.73(0.66-0.81)$ & $0.80(0.62-1.05)$ & & \\
\hline $3+$ & $0.66(0.59-0.74)$ & $0.76(0.58-0.98)$ & & \\
\hline \multicolumn{5}{|l|}{$\mathrm{N}^{\circ}$ chronic conditions } \\
\hline 0 & 1 & 1 & - & - \\
\hline 1 & $1.37(1.28-1.46)$ & $1.17(0.97-1.41)$ & & \\
\hline $2+$ & $1.96(1.72-2.24)$ & $1.48(1.04-2.10)$ & & \\
\hline Cancer $^{2}$ & - & - & $1.13(0.95-1.34)$ & $1.30(0.70-2.40)$ \\
\hline Heart disease ${ }^{2}$ & $1.57(1.39-1.76)$ & $1.14(0.89-1.46)$ & $1.60(1.39-1.85)$ & $1.00(0.71-1.42)$ \\
\hline Verbal fluency (range 0-62) & - & - & $1.01(1.00-1.02)$ & $0.99(0.97-1.00)$ \\
\hline \multicolumn{5}{|l|}{ Body mass index } \\
\hline Under/normal weight & 1 & 1 & - & - \\
\hline Overweight & $1.21(1.13-1.29)$ & $0.91(0.74-1.13)$ & & \\
\hline Obese & $1.57(1.46-1.68)$ & $1.24(0.98-1.55)$ & & \\
\hline Urinary incontinence ${ }^{2}$ & $1.61(1.52-1.70)$ & $2.61(1.99-3.42)$ & - & - \\
\hline
\end{tabular}

OR odds ratio; $99 \% \mathrm{Cl} 99 \%$ confidence interval;

All models were adjusted for age.

${ }^{1}$ Models were stratified by sex only if a statistically significant interaction with sex was found - see Tables 2 and 3 for results of the test for interaction with sex for each of the risk factors.

${ }^{2}$ Not having the condition was defined as the reference category. 